\title{
T.O.F. LASER SCANNER FOR THE SURVEYING OF STATUES: A TEST ON A REAL CASE
}

\author{
G.Artese ${ }^{a}$, L. De Napoli ${ }^{b}$ and S.Artese ${ }^{c}$ \\ ${ }^{a}$ Department of Civil Engineering, University of Calabria, Rende, Italy - g.artese@ unical.it \\ ${ }^{\mathrm{b}}$ Department of Mechanical, Energy and Management Engineering, University of Calabria, Rende, Italy - \\ luigi.denapoli@unical.it \\ ${ }^{\mathrm{c}}$ Department of Informatics, Modelling, Electronics and Systems Engineering, University of Calabria, Rende, Italy - \\ serena.artese@unical.it
}

KEY WORDS: Laser scanning, Cultural Heritage, Augmented Reality, City Model, 3D Modelling, Multiresolution, Representation

\begin{abstract}
:
The contribution regards the surveying of two statues of famous contemporary sculptors that have been placed in the central zone of Cosenza, which has been transformed in an open air museum. To realize a 3-D representation of the museum, different methodologies have been used, based on classical surveying (total stations and GNSS), image data and range data.

The increasing performances of the new models of Time Of Flight (T.O.F.) laser scanners allow to build accurate models also for medium-size objects; on the other hand, the recent techniques of 3D modeling enable the processing of large amount of data and the effective removal of noises. Thus, if an extreme accuracy is not required, one can think to use the T.O.F. laser scanner, also for the surveying of statues. For the acquisition of the surfaces of the statues, two different types of laser scanning have been used: the Leica Scan StationC10, based on Time Of Flight, and the Minolta VIVID 300 triangulation scanner. In the paper, the comparison between the results obtained by using the different techniques is described.
\end{abstract}

\section{INTRODUCTION}

In the last years, the request for digital documentation of works of art has increased exponentially. Multi-resolution 3D models are more and more used for the representation of complex sites. This is allowed thanks to the evolution of new sensors, along with the increasing computing power and the evolvement of techniques for the management of very large data sets.

The most used methodologies are basically based on image data (Remondino and El-Hakim, 2006) and range data (Beraldin et al., 1997). Total Stations and GNSS receivers are still used for georeferencing and to obtain control points. Different methodologies are ever more integrated, to take advantage from each technique (El-Hakim et al., 2004; Remondino et al., 2009). For the image data, featureless approaches are currently used (Hammoudi and Dornaika, 2011), whilst for range data the classical ICP method is still used by the most diffused software (Besl and McKay, 1992; Chen and Medioni, 1992; Zhang, 1994). The influence of materials should be anyway taken into account (Godin et al., 2001).

The use of T.O.F. laser scanners for the surveying of very large statues or of regular parts of large statues is not new. These surveyings are generally integrated by close range scans, obtained by triangulation instruments, for the irregular surfaces (Ressl, 2007). The surveying of a complex statue has been generally performed by using several scans, retro-reflecting targets and images. The most diffused software give automatically low precision models. The effort for obtaining more accurate results is generally very high (Vozikis et al., 2004).

In the last years, the increasing performances of the new models of TOF laser scanners allow to build accurate models also for medium-size objects; on the other hand, the recent techniques of $3 \mathrm{D}$ modeling enable the processing of large amount of data and the effective removal of noises. Thus, if an extreme accuracy is not required, one can think to use the TOF laser scanner both for city modeling and for the surveying of statues, by avoiding the use of triangulation instruments.

In the framework of the activities in the field of Cultural Heritage in Southern Italy, several monuments and works of art have been surveyed by the Geomatics Lab of the University of Calabria, Italy (Artese et al., 2003, 2005, 2006). The most recent initiatives concern a series of statues of famous contemporary sculptors that have been placed in the central zone of Cosenza, Italy, in order to create an open air museum. In the following, the surveying of two statues, having different characteristics, is described; the surveying has been performed by using both T.O.F. and triangulation scanners. The comparison between the results obtained by using the different techniques is described.

\section{THE STATUES AND THE SURROUNDING ENVIRONMENT}

\subsection{The City}

Sited in Calabria, southern Italy, Cosenza was known in antiquity as the Athens of Calabria, thanks to its cultural past: the Accademia Cosentina, e.g., was one of the very first academies to be founded in Europe (1511).

The city is located at the confluence of two rivers, the Busento and the Crathis, and is surrounded by seven hills. Alaric, king of the Goths, died in 410 in Cosenza and his body was, according to legend, buried under the riverbed of the Busento. The stream was temporarily diverted from its course while the grave was dug wherein the Gothic chief and some of his most precious spoils were interred (Jordanes, 552).

\subsection{The M.A.B.}

The M.A.B. (Open Air Bilotti Museum) consists of several sculptures, sited in the pedestrian area of the city, along the main road. The works of art, realized by famous artists of XXth and XXIth centuries (de Chirico, Dalì, Greco, Manzù, Sosno, 


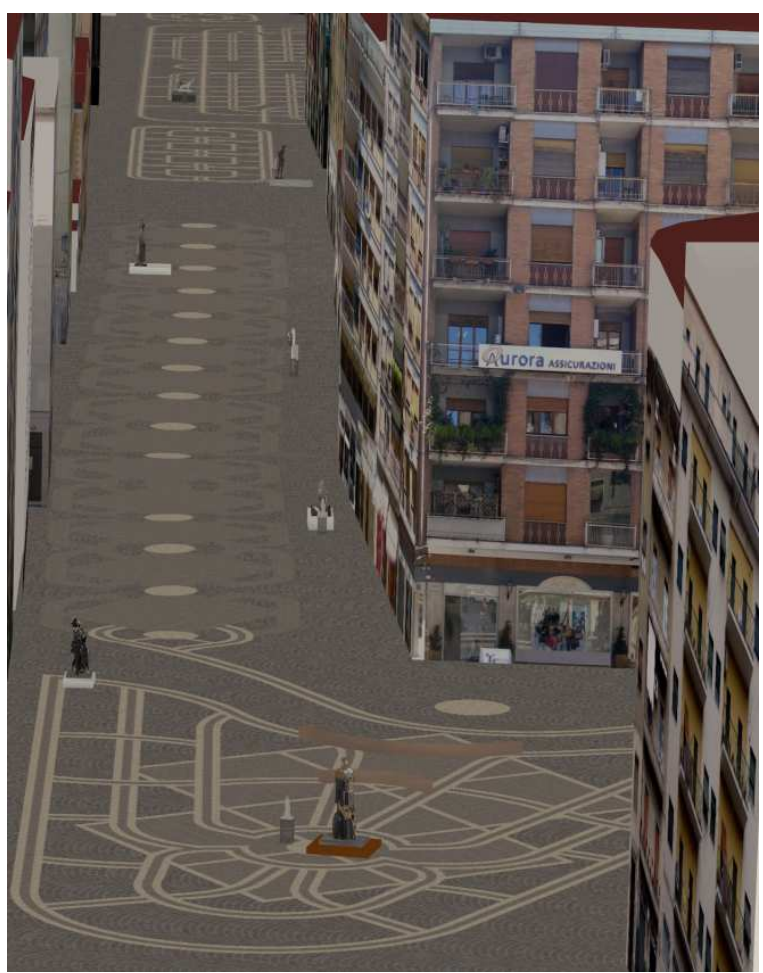

Figure 1. The 3D model of the M.A.B.

Consagra), are a donation of the patrons Carlo Bilotti and Enzo Bilotti. The 3D model has been used for documentation, representation and animation.

An urban open-air museum is a peculiar site, where the works of art are surrounded by buildings; the size, shape and textures of buildings contributes to create the museum, which is the fusion of the works of art and of the surrounding architecture. For this reason, the surveying cannot be limited to the works of art, but it must regard a portion of the city, the streets and the squares, the single buildings and finally the statues.

\subsection{The Statues}

Two statues are taken into account: the first one, the "Wolf of Sila", which author is Mimmo Rotella, is a marble object, characterized by flat surfaces; the second one, "St. George and the Dragon" by Salvador Dalì, is characterized by the use of bronze and brass, which allowed to differentiate in a particular way St. George, the horse and the dragon.

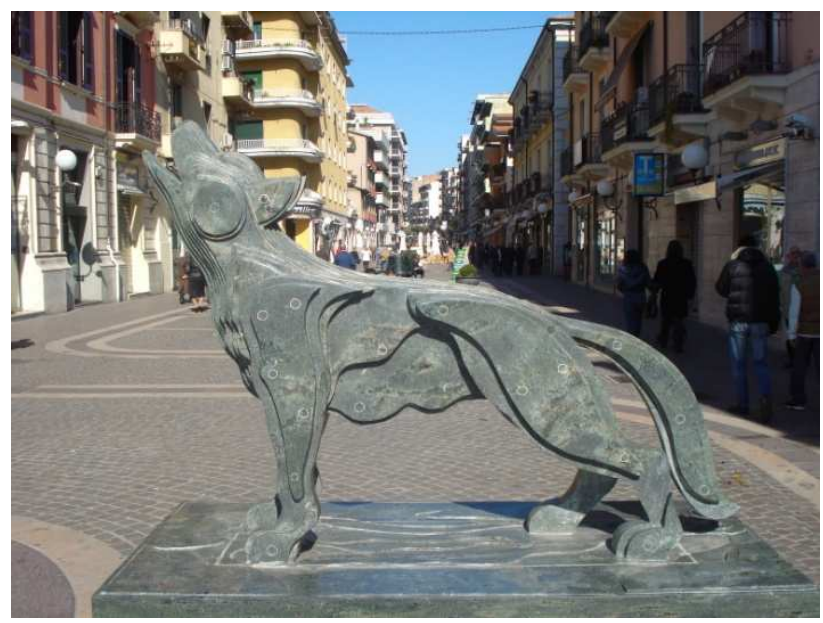

The Wolf of Sila has been realized with green marble. The dimensions (lenght, width and height) are $147 \times 38.5 \times 120 \mathrm{~cm}$ for the statue and $180 \times 88 \times 17 \mathrm{~cm}$ for the basement. The idea came to the artist during one of his holidays in the mountains of Sila, at the request of the collector Enzo Bilotti. Rotella created the wooden prototype, shortly before his death, and decided that the specimen final product would be in green marble.

The animal, symbol of the city, is represented by the artist while howling. It's simple and linear in shape, completely lack the physical features of the beast, but the whole body seems to be a movement path made with engraved lines and sinuous curves. It is a work that shows not only artistic merit, but also socio-anthropological value, identification of cultural roots.

The statuary group of St. George and the Dragon has been realized by using league of bronze and brass alloy. The

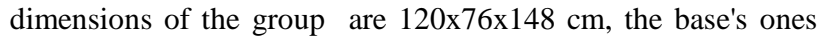
are $136 \times 82 \times 8 \mathrm{~cm}$.

St. George rides his horse and with a spear hits the dragon, caught between the paws of the horse in the background, behind the main scene, a small female figure is the princess who is saved. It is a sculpture that blends wonderfully the three subjects (the Holy One, his horse and the Dragon) in a plastic movement that refers to the Christian tradition of the life of St. George and the saint is depicted without a face, as if to remind the dummies of de Chirico. The flying dragon is a symbol of immortality, because its function is to transport the immortals, the character who stabs him is a mysterious creature who takes possession of such immortality by defeating the fair.

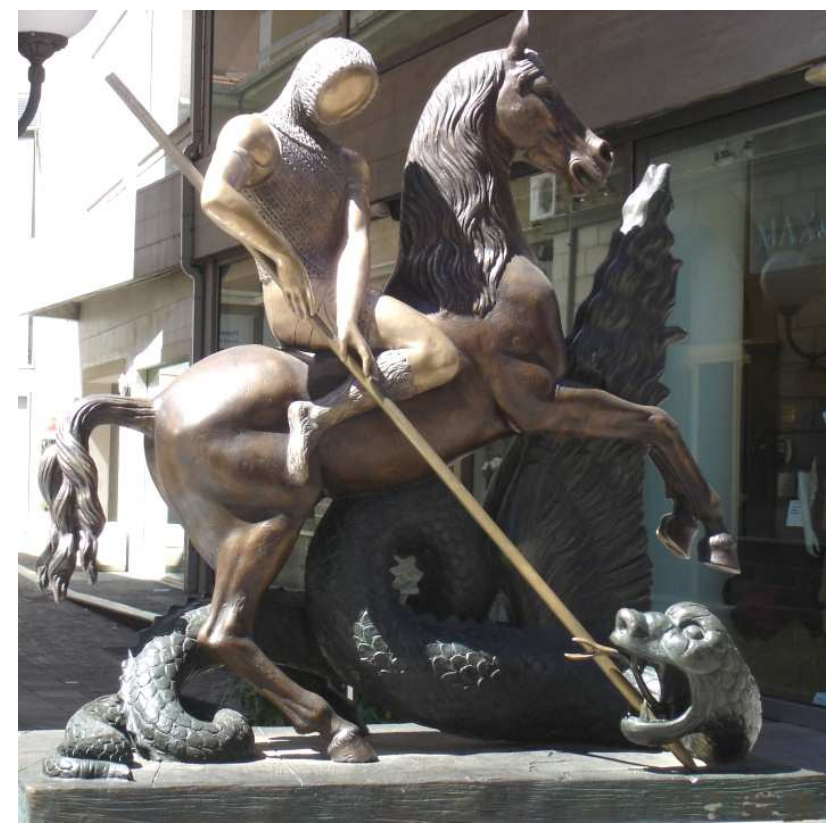

Figure 3. St. George and the Dragon

Looking at the composition it can be seen that the color of the bronze changes in the various plans to scale it up, as if the lower level lacked any glimmer of light that, instead, shines in the figure that destroys the dragon.

\section{SURVEYING AND DATA PROCESSING}

In order to represent a large and complex site like the M.A.B., several models, having different Level Of Details must be

Figure 2. The Wolf of Sila 
created. For this aim different methodologies has been used, based on classical surveying (total stations and GNSS), image data (aerial and close range photogrammetry), range data (aerial LIDAR, Time of Flight based Terrestrial Laser Scanner, Triangulation Laser Scanner).

The building facades, the paving and the whole open-air museum have been surveyed with a Time of Flight Laser Scanner, in order to optimize the time needed for the data acquisition and processing.

To obtain the surfaces of the statues, shielded during the acquisitions, two different types of laser scanners have been used: the Leica Scan Station C10, based on time of flight, and the Minolta VIVID 300 triangulation scanner (see Table 1). For every statue, the 3D models have been obtained by using three scans of $\mathrm{C} 10$, while 60 scans have been necessary to obtain the model using the VIVID 300.

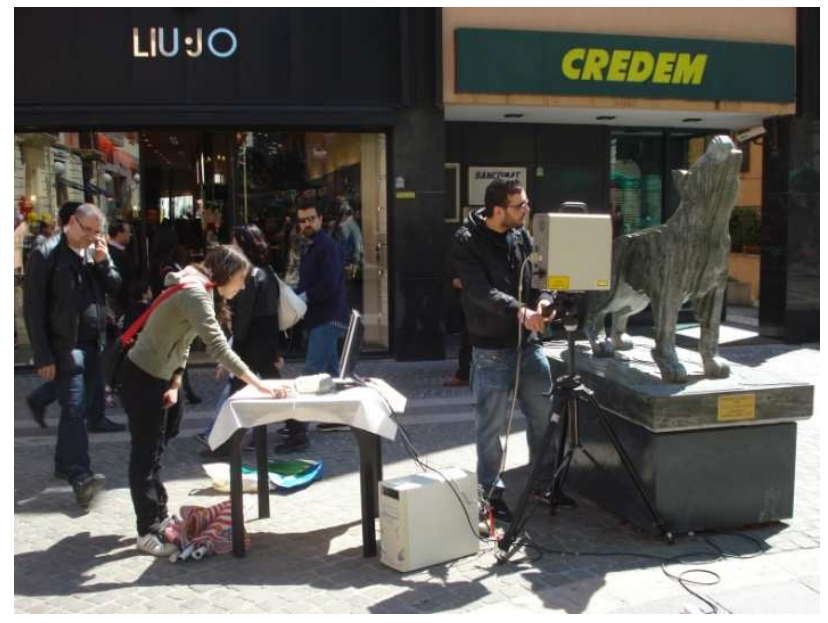

Figure 4. The positioning of the Vivid 300 before the shadowing of the statue

The data processing has been performed by using commercial programs (Rapidform ${ }^{\mathrm{TM}}$, Geomagic Studio $12^{\mathrm{TM}}$ ). In order to compare the performances of T.O.F. and Triangulation scanners, the same operations have been made, and several nurbs interpolating the point clouds have been obtained. The comparison has been performed taking into account the statistics generated by the used programs.

\begin{tabular}{|l|l|l|}
\hline & VIVID 300 & C10 \\
\hline Sampled points & $\begin{array}{l}200 \mathrm{x} \text { 200 } \\
\text { points/shot }\end{array}$ & $\begin{array}{l}\text { Up to 50,000 } \\
\text { points/sec }\end{array}$ \\
\hline Accuracy & 0.45 to $1 \mathrm{~mm}$ & $4 \mathrm{~mm}$ \\
\hline $\begin{array}{l}\text { Spacing between } \\
\text { points }\end{array}$ & $\begin{array}{l}\text { da } 0.95 \text { a } 1.91 \\
\mathrm{~mm}\end{array}$ & $<1 \mathrm{~mm}$ \\
\hline Min / Max range & 55 to $120 \mathrm{~cm}$ & 0.1 to $300 \mathrm{~m}$ \\
\hline $\begin{array}{l}\text { Min /Max Field } \\
\text { of View }\end{array}$ & $185 / 395 \mathrm{~mm}$ & $\begin{array}{l}\text { Max } \\
360^{\circ} \text { Horizontal } \\
270^{\circ} \text { Vertical }\end{array}$ \\
\hline
\end{tabular}

Table 1. Vivid 300 Minolta and Leica C10 characteristics

\section{TEST RESULTS}

\subsection{St. George and the Drake}

For the statuary group of St. George and the Dragon, the comparison of the results obtained by the T.O.F. and triangulation scanner has been performed for three different zones, showing different surface characteristics. Figure 5 shows the whole point cloud obtained by the $\mathrm{C} 10$ scans; in figure 6 we can observe the textured model positioned in the $3 \mathrm{D}$ city model.

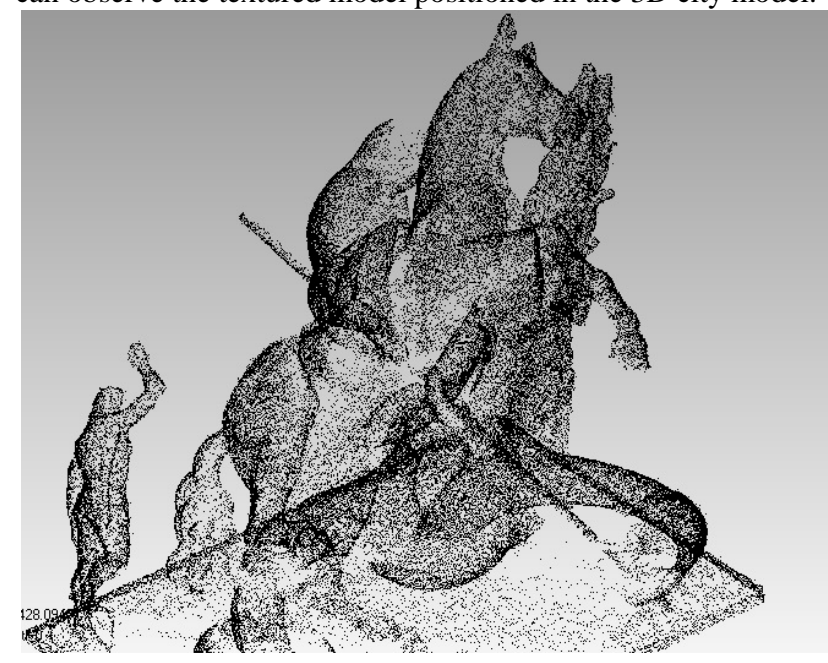

Figure 5. The point cloud of St. George and the Drake obtained with three scans of T.O.F. laser scanner

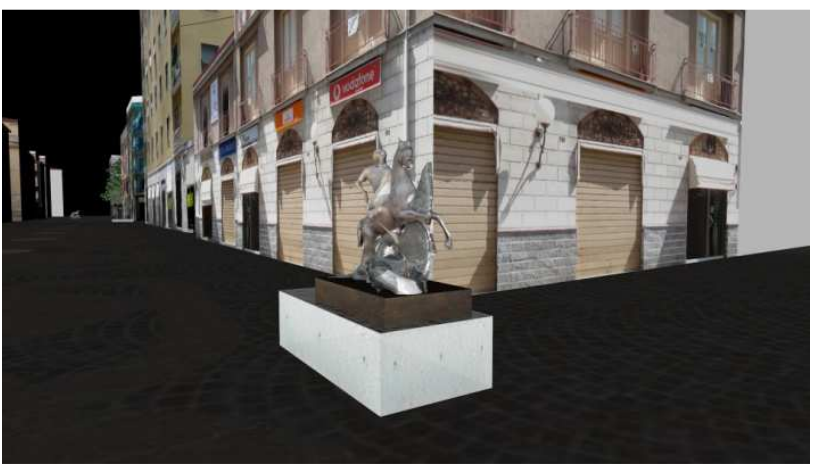

Figure 6. The model of St. George and the Drake obtained with C10 scans in the city model

The first comparison has been performed taking into account a zone of the left wing of the dragon, characterized by a dark and dull surface. Figures 7 and 8 show, respectively, the deviations between the points acquired by $\mathrm{C} 10$ scan and the model and the ones between the points acquired by VIVID 300 scan and the model. The second comparison regards the chest of the horse; the results are reported in the figures 9 and 10. Figures 11 and 12, finally, show the deviations for the head of St. George, characterized by a shiny surface.

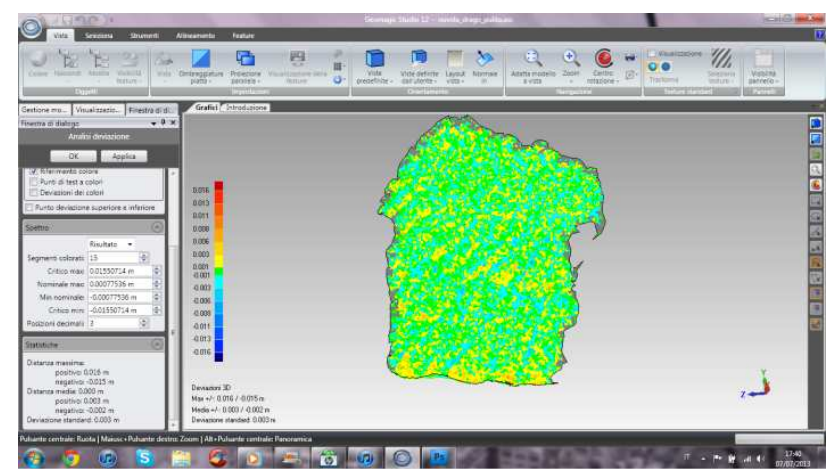

Figure 7. The deviations points-model (from the $\mathrm{C} 10$ scans) for the wing of the dragon 


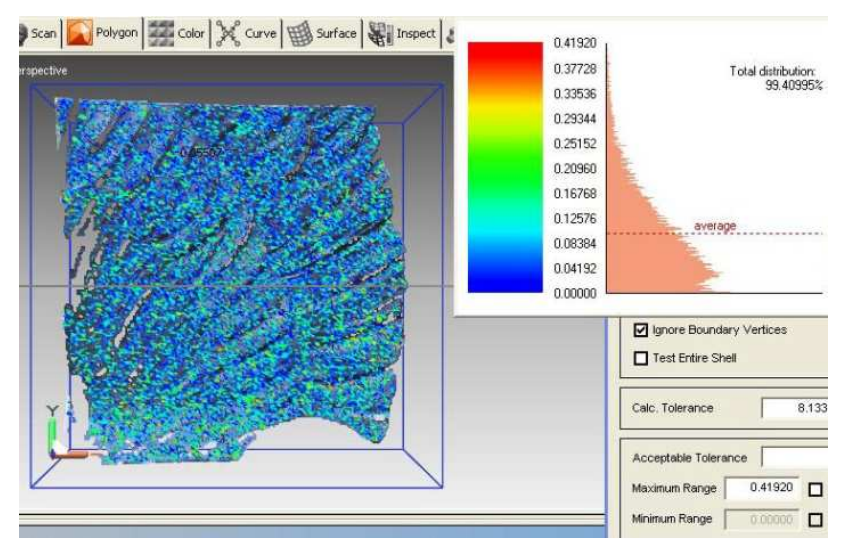

Figure 8. The deviations points-model (from the VIVID 300 scans) for the wing of the dragon

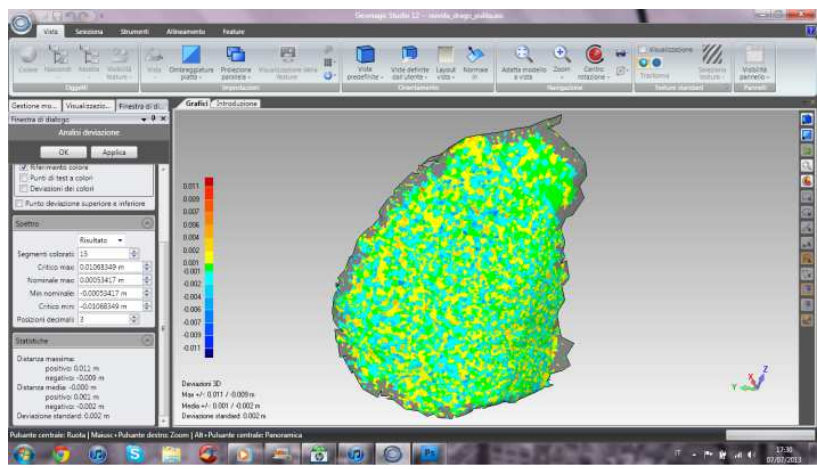

Figure 9. The deviations points-model (from the $\mathrm{C} 10$ scans) for the chest of the horse

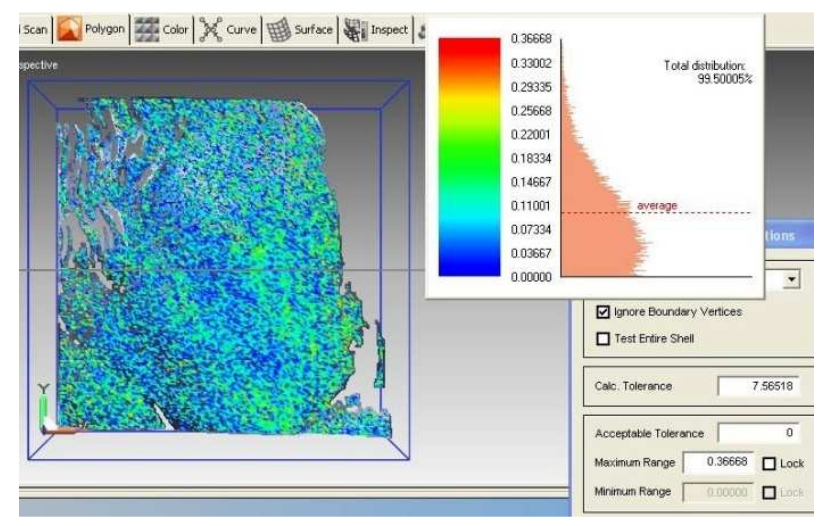

Figure 10. The deviations points-model (from the VIVID 300 scans) for the chest of the horse

\begin{tabular}{|l|c|c|c|}
\hline & $\begin{array}{c}\text { Average of } \\
\text { absolute } \\
\text { values (mm) }\end{array}$ & $\begin{array}{c}\text { Maximum } \\
(\mathrm{mm})\end{array}$ & $\begin{array}{c}\text { St. Dev } \\
(\mathrm{mm})\end{array}$ \\
\hline Drake Wing C10 & 2.5 & 16 & 3 \\
\hline Drake Wing VIVID 300 & 0.1 & 0.4 & 0.1 \\
\hline Horse Chest C10 & 1.5 & 11 & 2 \\
\hline Horse Chest VIVID 300 & 0.1 & 0.37 & 0.1 \\
\hline St. George Head C10 & 1 & 9 & 2 \\
\hline $\begin{array}{l}\text { St. George Head VIVID } \\
\text { 300 }\end{array}$ & 0.07 & 0.35 & 0.1 \\
\hline
\end{tabular}

Table 2. Deviations for the statuary group St. George and the Drake

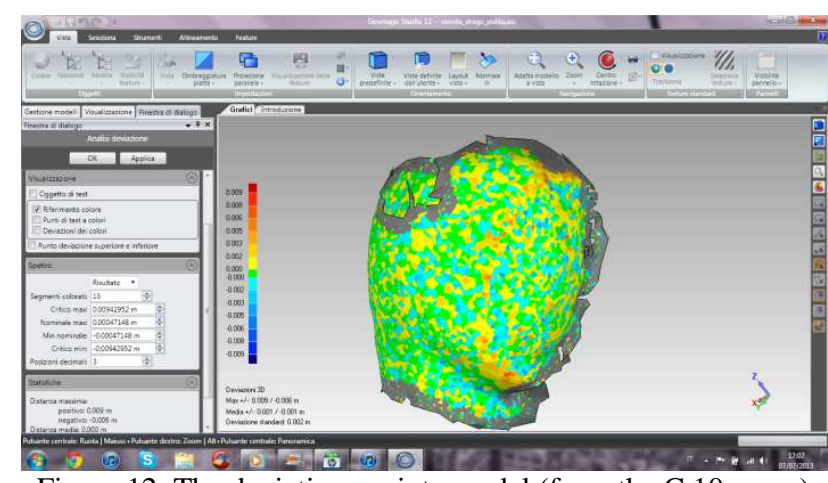

Figure 12. The deviations points-model (from the $\mathrm{C} 10$ scans) for the head of St. George

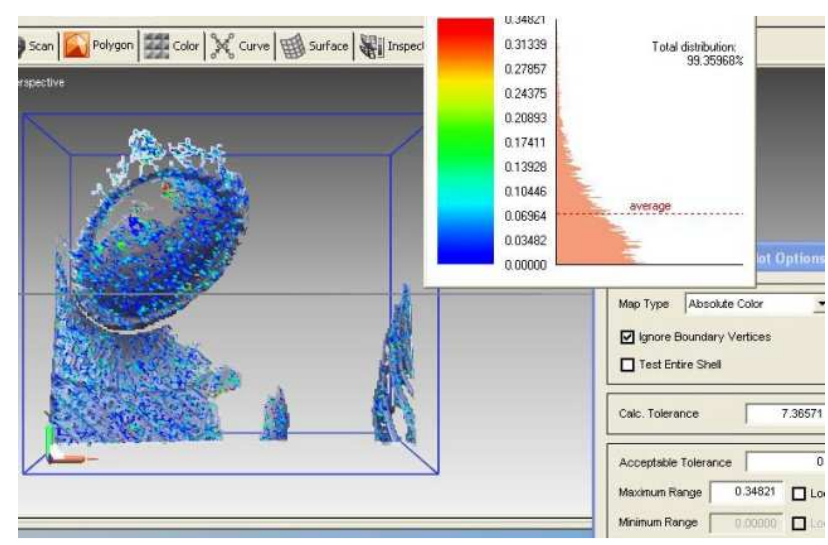

Figure 11. The deviations points-model (from the VIVID 300 scans) for the head of St. George

The comparison is summarized in table 2 . It is possible to observe that the performances of the triangulation scanner are better and almost independent of the surface, while the T.O.F. shows increasing accuracies passing from the dark surface (drake wings) to the shiny surface (head of St. George).

The average of the deviations has negligible values.

\subsection{The Wolf of Sila}

For the statue The Wolf of Sila, the comparison of the results obtained by the T.O.F. and triangulation scanner has been performed for the zone of the head. Figure 13 shows the merge of 5 VIVID scans; in figure 14 we can observe the textured model positioned in the 3D city model.

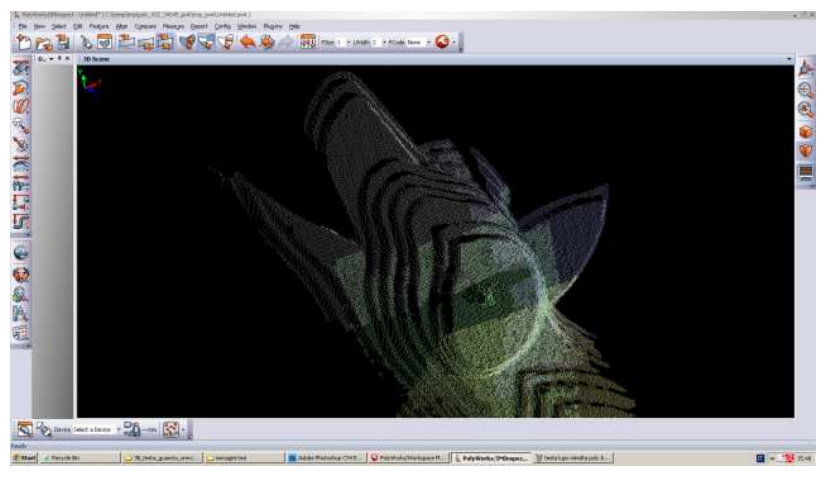

Figure 13. The merge of 5 VIVID 300 scans for the Wolf of Sila 


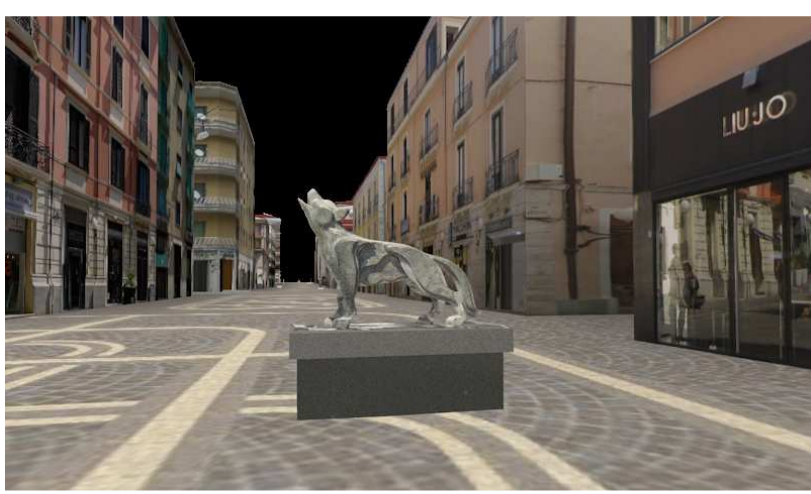

Figure 14. The model of the Wolf of Sila with C10 scans in the city model

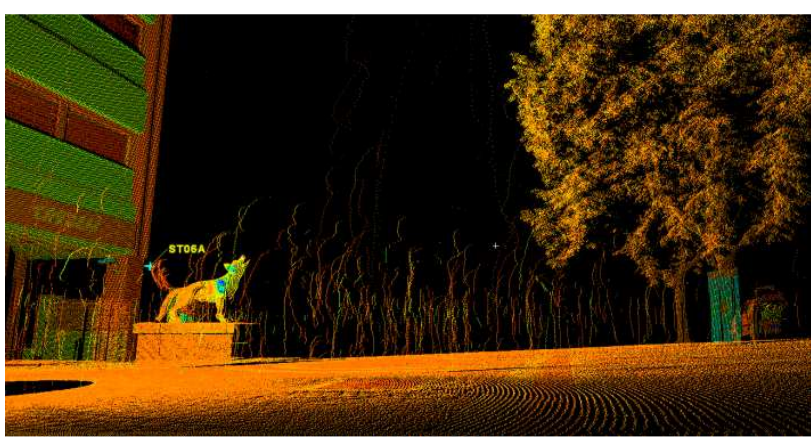

Figure 15. The point cloud of the Wolf of Sila and the surrounding zone, obtained with a scan of T.O.F. laser scanner

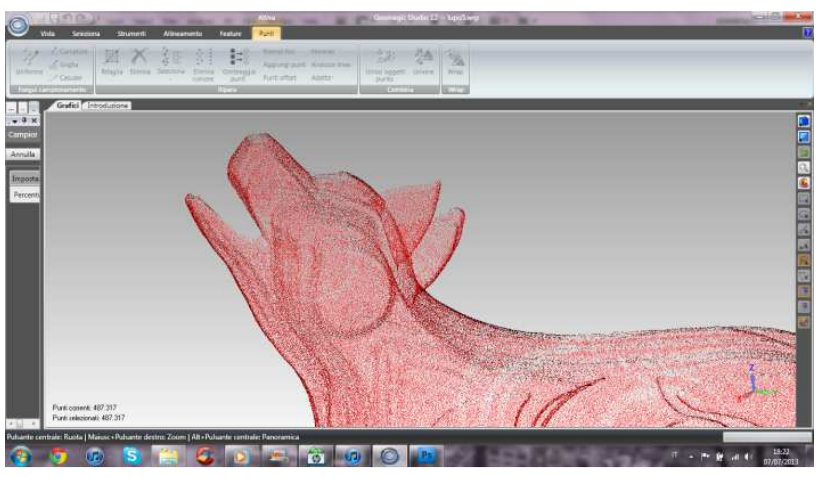

Figure 16. The point cloud of the Wolf of Sila, obtained with a scan of T.O.F. laser scanner

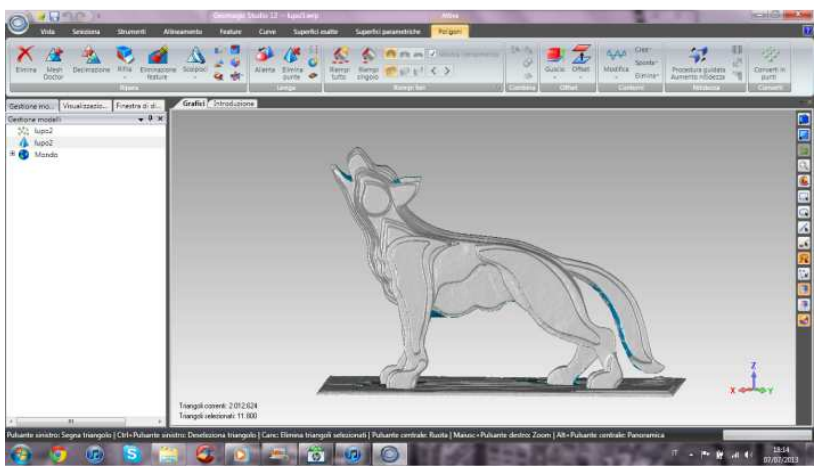

Figure 17. The model of the Wolf of Sila (from three C10 scans)

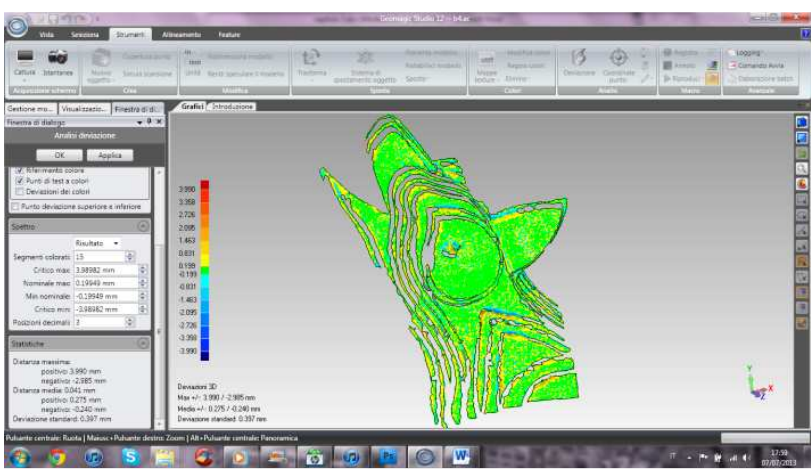

Figure 18. The deviations points-model (from the VIVID 300 scans) for the head of the Wolf of Sila

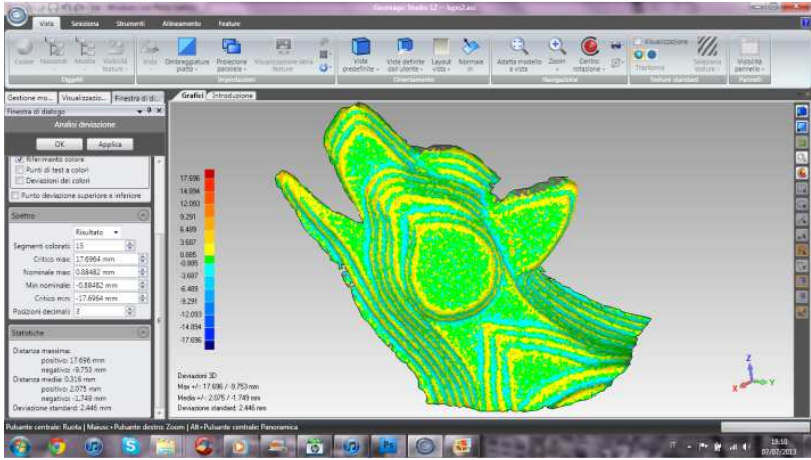

Figure 19. The deviations points-model (from the C10 scans) for the head of the Wolf of Sila

Figures 15 and 16 show the point cloud obtained by C10 scans; figure 17 is a view of the relevant model.

The deviations are shown in figure 18 (VIVID 300) and 19 (C 10). The comparison is summarized in table 3 . It has to be underlined that the statue has a peculiar form, composed by several plane surfaces and with sharp edges. The material is green marble: this implies some systematic errors due to apparent penetration of laser beam, above all for TOF scan. Another remark regards the model obtained in semiautomatic way by using Geomagic ${ }^{\mathrm{TM}}$. The edges are too much smoothed, so maximum negative deviation $(-17.8 \mathrm{~mm})$ is very different from the positive one ( $9.8 \mathrm{~mm}$ ).

The triangulation scanner shows a somewhat similar behaviour. Also in this case the maximum deviations are distributed along the edges, but the smoothing performed by software is less influent. The presence of border effects causes higher deviation values respect to the other statues: a manual refinement of the model is requested.

\begin{tabular}{|l|l|l|l|}
\hline & $\begin{array}{c}\text { Average of } \\
\text { absolute } \\
\text { values (mm) }\end{array}$ & $\begin{array}{c}\text { Maximum } \\
(\mathrm{mm})\end{array}$ & $\begin{array}{c}\text { St. Dev } \\
(\mathrm{mm})\end{array}$ \\
\hline Wolf Head C10 & 1.85 & 17.7 & 2.4 \\
\hline Wolf Head VIVID 300 & 0.25 & 3.99 & 0.4 \\
\hline
\end{tabular}

Table 3. Deviations for the statuary group St. George and the Drake

\section{CONCLUSIONS}

Two statues sited in the $M A B$ open air museum of Cosenza, Italy, has been surveyed. The comparison between the results 
obtained by using a T.O.F. and a triangulation laser scanner has been carried out. The data processing has been performed by using commercial programs. The use of automated techniques allows to rapidly obtain models with just three T.O.F. scans. This rapidity is paid with greater deviations, above all if a priori known geometry (e.g. sharp edges) is not imposed. The obtained models are really effective for representation aims, above all when they are textured. The use of triangulation scanner, which implies many scans and long processing work, is still mandatory for documentation or restoration aims.

\section{REFERENCES}

Artese G., Achilli V., Abitrante M., 2003. Dynamic 3D representation of architecture as a design tool: the old town of Cosenza, International Archives of Photogrammetry and Remote Sensing - Vol. XXXIV 5/W12 Comm. V , pp. 28-33

Artese G., Achilli V., Boatto G., Fabris M., Salemi G., Trecroci A., 2005. Peter Bernini in Calabria: the Sculptures of the "SS. Pietro e Paolo Church" in Morano Calabro. Proc. CIPA XX International Symposium - CIPA International Archives for Documentation of Cultural Heritage - Vol. XX, pp. 91-94

Artese G., De Napoli L., Trecroci A., 2006. Influenza dei materiali sulla precisione del laser scanner: il rilievo della statua "S.Giorgio e il Drago" di Salvador Dalì, Proceedings of 10th Asita Conference, Bolzano, Vol. 1, pp. 85-90

Beraldin J.-A., Cournoyer L., Rioux M., Blais F., El-Hakim S.F., Godin G., 1997. Object model creation from multiple range images: acquisition, calibration, model building and verification, Proc. 1st Int'l Conf. on 3-D Digital maging and Modeling, IEEE, 1997, pp. 326-333

Besl P.J., McKay N.D., 1992. A Method for Registration of 3-D Shapes, IEEE Transactions on Pattern Analysis and Machine Intelligence, 14(2), pp. 239-256

Chen Y., Medioni G., 1992. Object Modeling by Registration of Multiple Range Images, Image and Vision Computing, 10(3), pp. $145-155$

El-Hakim S.F., Beraldin J.A., Picard M., Godin G., 2004. Detailed 3D reconstruction of large-scale heritage sites with integrated techniques., IEEE Computer Graphics and Application, 24(3), 21-29

El-Hakim, S., Remondino, F., 2006. Image-Based 3d Modelling: A Review, The Photogrammetric Record 21(115): 269-291

Godin G., Rioux M., Beraldin J.-A., Levoy M., Cournoyer L., Blais F., 2001. An assessment of laser range measurement on marble surfaces, Proceedings 5th Conference on Optical $3 D$ Measurement Techniques, Wien, Austria, Oct. 1-4, pp. 49-56

Hammoudi K., Dornaika F., 2011. A Featureless Approach to 3D Polyhedral Building Modeling from Aerial Images, Sensors 11, pp. 228-259.

Jordanes, 552. The Origin and Deeds of the Goths (De origine actibusque Getarum), translated by $\mathrm{C}$. Mierow, Princeton University Press, 1908.
Remondino, F., Gruen, A., von Schwerin, J., Eisenbeiss, H., Rizzi, A., Girardi, S., Sauerbier, M., Richards-Rissetto, H., 2009. Multi-Sensor 3d Documentation of the Maya site Of Copan, Proceedings of 22nd CIPA Symposium, October 11-15, 2009, Kyoto, Japan

Ressl C., 2007. Reconstruction of the Pegasus Statue on Top of the State Opera House in Vienna using Photogrammetry and Terrestrial and Close-Range Laser Scanning, Lasers in the Conservation of Artworks, Springer proceedings in physics Volume 116, pp 535-542.

Vozikis G., Haring A., Vozikis E. and Kraus K., 2004. Laser Scanning: A New Method for Recording and Documentation in Archaeology, Proceedings of FIG Working Week, Athens, Greece, May 22-27, 2004, pp. 1-16

Zhang Z., 1994. Iterative Point Matching for Registration of Freeform Curves and Surfaces, International Journal of Computer Vision, 13(2), pp. 119-152.

http://www.geomagic.com/en/products/studio/overview (9 Lug. 2013)

Non-Contact 3d Digitizer Vivid 300/Vi-300 Instruction Manual http://sensing.konicaminolta.us/wpcontent/uploads/2011/05/VI VID300_Hard.pdf (9 Lug. 2013)

Leica ScanStation C10 Datasheet, http://hds.leicageosystems.com/downloads123/hds/hds/ScanStation\%20C10/br ochures-datasheet/Leica_ScanStation_C10_DS_en.pdf (9 Lug. 2013) 